\title{
Instrumentos para Monitoramento e Avaliação das Políticas e Programas do Ministério da Educação
}

\section{Introdução}

A avaliação de políticas, programas e ações é uma das etapas mais importantes e fator imprescindível no ciclo da gestão governamental e vem se constituindo em uma das principais ferramentas gerenciais para o aprimoramento das políticas públicas e aperfeiçoamento da ação estatal. Seu objetivo é assegurar o aperfeiçoamento contínuo das políticas públicas como um todo, especialmente dos programas sociais, provendo subsídios para a correção de falhas, tanto de concepção como de execução, permitindo que os resultados desejados junto ao público-alvo ocorram efetivamente. Portanto, a qualidade da informação é fundamental para a análise da política. A contínua melhoria da qualidade das políticas públicas e sua efetividade junto à população é um princípio que eleva os desafios para a gestão pública e ressalta a importância da avaliação da ação governamental.
Dessa forma, o aprimoramento de sistemas de informação e documentação que compreendem estatísticas, avaliações educacionais, práticas pedagógicas e de gestão das políticas educacionais, bem como a produção de informações claras e confiáveis aos gestores, pesquisadores, educadores e público em geral a respeito das políticas públicas de educação, constitui importante estratégia de desenvolvimento de uma cultura de avaliação e de busca por mais transparência e responsabilização da gestão governamental, por meio do fornecimento de dados e indicadores quantitativos e qualitativos. Em síntese, os processos avaliativos constituem um sistema que permite a integração das diversas dimensões da realidade avaliada, bem como o alcance dos objetivos dos diversos instrumentos e modalidades, informando resultados do processo de ensino e do processo de aprendizagem, contribuindo para uma descrição mais precisa da realidade escolar. 
No campo da educação, a avaliação tem ocupado papel central nas políticas educacionais em curso no País. Pode-se considerar que o Ministério da Educação (MEC) tem assumido a responsabilidade atribuída pela Lei de Diretrizes e Bases da Educação (LDB) de coletar, analisar e disseminar informações sobre a educação, bem como de assegurar processo nacional de avaliação do rendimento escolar no ensino fundamental, médio e superior, em colaboração com os sistemas de ensino, objetivando a definição de prioridades e a melhoria da qualidade do ensino.

Percebe-se uma valorização crescente das políticas de avaliação de sistemas públicos de educação que, geralmente aferidas por meio de provas de larga escala aplicadas aos alunos, quando conjugadas a instrumentos de coleta de dados, informam resultados do processo de ensino e do processo de aprendizagem, revelando um tipo de descrição mais precisa da realidade escolar. Além disso, a utilização dos indicadores e informações resultantes dos censos educacionais e das avaliações realizadas pelo MEC tem possibilitado a identificação de prioridades, além de fornecer parâmetros mais precisos para a formulação e o monitoramento das políticas, orientando a definição de critérios para a atuação supletiva e redistributiva do Governo Federal com vistas à superação das desigualdades regionais e das deficiências dos sistemas de ensino.

Neste sentido, há um acervo muito expressivo de fontes de estatísticas da educação brasileira e instrumentos de monitoramento e avaliação da ação governamental na área. Alguns desses instrumentos encontram-se elencados no quadro a seguir.

\section{- OUADRO 1: PRINCIPAIS FONTES DE INFORMAÇÃO PARA MONITORAMENTO E AVALIAÇÃO DA EDUCAÇÃO}

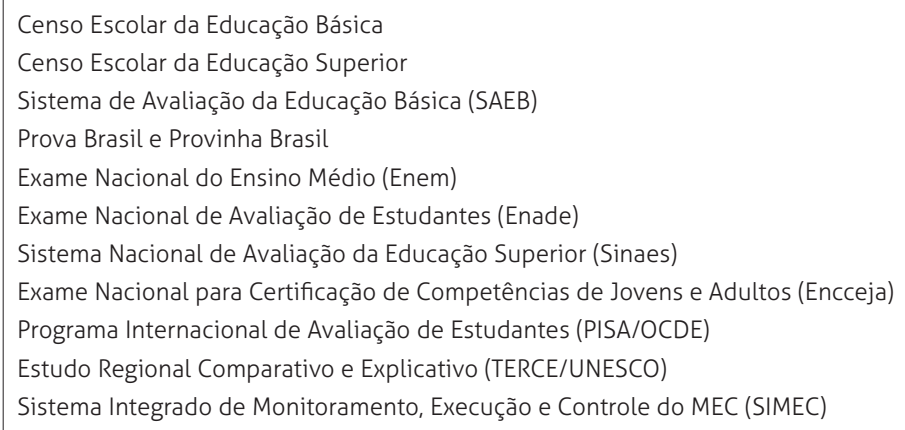

Revista Brasileira de Monitoramento e Avaliação | Número 5 | Janeiro-Junho de 2013 


\section{CENSO ESCOLAR DA EDUCAÇÃO BÁSICA}

O Censo Escolar da Educação Básica é um levantamento de dados estatístico-educacionais de âmbito nacional, uma pesquisa declaratória realizada anualmente pelo Instituto Nacional de Estudos e Pesquisas Educacionais Anísio Teixeira (Inep)², sendo obrigatório aos estabelecimentos públicos e privados de educação básica, conforme determina o art. $4^{\circ}$ do Decreto $n^{\circ}$ $6.425 / 2008$. Trata-se do principal instrumento de coleta de informações da educação básica, que abrange todas as etapas e modalidades desse nível de ensino: ensino regular (educação infantil e ensinos fundamental e médio), educação especial e educação de jovens e adultos (EJA). É realizado anualmente com a colaboração das Secretarias Estaduais e Municipais de Educação e com a participação de todas as escolas públicas e privadas do País.

O Censo Escolar coleta dados detalhados sobre escolas, turmas, professores e alunos de todas as etapas e modalidades de ensino da educação básica, em todo o País, compondo um quadro detalhado que permite aos pesquisadores e aos órgãos de governo verificarem a situação atual e a evolução da educação básica, assim como os resultados das políticas em curso. É considerado o mais relevante e abrangente levantamento estatístico sobre a educação básica no País. Além de serem utilizados para traçar um panorama nacional da educação básica, os dados coletados constituem uma fonte completa de informações utilizada para a formulação de políticas, o desenho de programas na área da educação, bem como para a definição de critérios para a atuação supletiva do MEC às escolas, aos estados e aos municípios, mediante a transferência de recursos públicos para merenda e transporte escolar, distribuição de livros, implantação de bibliotecas, instalação de energia elétrica, Programa Dinheiro Direto na Escola (PDDE) e Fundo de Manutenção e Desenvolvimento da Educação Básica e de Valorização dos Profissionais da Educação (Fundeb).

No âmbito do Censo Escolar, cabe destacar a implantação, em 2008, do Sistema de coleta on-line do Censo Escolar da Educação Básica - Educacenso. Trata-se de um sistema eletrônico de coleta de informações educacionais composto por um aplicativo web, que permite a coleta, a migração e a alteração de dados educacionais das escolas em todo o território nacional e por um banco de dados relacional, que armazena de forma sistemática todas estas informações. Constitui um banco de dados único, de base nacional, que é alimentado por dados e informações que vêm diretamente das escolas, por meio da internet. O Educacenso inovou no processo e no conteúdo da coleta de dados do sistema educacional brasileiro, constituindo-se no mais completo cadastro de escolas, alunos e docentes do País. A construção de um banco de dados com informações individualizadas amplia as possibilidades de comunicação com outras bases de dados do Governo Federal. O novo desenho metodológico e a utilização de recursos de tecnologia da informação permitiram ampliar a precisão e a fidedignidade dos dados do Censo Escolar, o que possibilita 
a realização de ajustes na política educacional e maior efetividade do gasto público com a educação básica.

O levantamento nacional de dados educacionais, realizado pelo Censo Escolar 2012, apurou que em mais de 192 mil estabelecimentos de educação básica do País estão matriculados mais de 50 milhões de alunos, sendo $83,5 \%$ em escolas públicas e $16,5 \%$ em escolas privadas. No ano de 2013, dados preliminares apurados pelo Censo Escolar apontam que o Brasil possui 40.366 .076 estudantes matriculados na educação básica das redes pública estadual e municipal de ensino. As matrículas referem-se à educação infantil (creche e pré-escola), ao ensino fundamental ( $1^{\circ}$ ao $9^{\circ}$ ano), ao ensino médio, à educação profissional, à educação especial e à educação de jovens e adultos (nas etapas ensino fundamental e ensino médio).

\section{AVALIAÇÕES DA EDUCAÇÃO BÁSICA}

Para gerar dados e estudos educacionais, o Inep realiza levantamentos estatísticos e avaliativos em algumas etapas da educação básica, assim como na modalidade de educação de jovens e adultos. Os ins- trumentos que integram a Avaliação da Educação Básica no País são a Avaliação Nacional do Rendimento Escolar (Anresc/ Prova Brasil), a Avaliação Nacional da Educação Básica (Aneb) e a Provinha Brasil. De forma conjugada, essas três avaliações, associadas aos dados do Censo Escolar, possibilitam o cálculo do Índice de Desenvolvimento da Educação Básica (Ideb), que é calculado bienalmente para cada escola, por rede, por UF e Brasil, reunindo em um só indicador dois conceitos igualmente importantes para a qualidade da educação: fluxo escolar e médias de desempenho nas avaliações. As informações também permitem que metas sejam traçadas com o objetivo de atingir, em 2021, a média dos países desenvolvidos. Além disso, auxiliam professores e gestores a aperfeiçoarem o processo de ensino-aprendizagem.

A Provinha Brasil é uma avaliação diagnóstica do nível de alfabetização das crianças matriculadas no segundo ano de escolarização das escolas públicas brasileiras. Essa avaliação ocorre em duas etapas, uma no início e a outra ao término do ano letivo. Essa metodologia de aplicação em períodos distintos possibilita aos professores e gestores educacionais a realização de um diagnóstico mais preciso para

2 O Inep é uma autarquia federal vinculada ao MEC, cuja missão é promover estudos, pesquisas e avaliações sobre o Sistema Educacional Brasileiro com o objetivo de subsidiar a formulação e implementação de políticas públicas para a área educacional.

Revista Brasileira de Monitoramento e Avaliação | Número 5 | Janeiro-Junho de 2013 
conhecimento do que foi agregado na aprendizagem das crianças, em termos de habilidades de leitura dentro do período avaliado, de modo a intervirem de forma mais eficaz no processo de alfabetização, aumentando as chances de que todas as crianças, até os oito anos de idade, saibam ler e escrever. Em 2013 as escolas de todo - País receberam kits impressos para a aplicação da Provinha Brasil de Leitura e U Matemática. A quantidade de kits disponibilizados para as redes é calculada com base no total de estudantes de $2^{\circ} \mathrm{ano} / 2^{\mathrm{a}}$ série regular declarado pelas escolas urbanas e rurais ao Censo Escolar. Também são consideradas as turmas multisseriadas e o período de aplicação da Provinha Brasil é facultado a cada rede de ensino.

O Sistema de Avaliação da Educação Básica (Saeb) tem como principal objetivo avaliar a educação básica brasileira e contribuir para a melhoria de sua qualidade e para a universalização do acesso à escola, oferecendo subsídios concretos para a formulação, a reformulação, o monitoramento e a avaliação das políticas públicas educacionais. Além disso, procura também oferecer dados e indicadores que possibilitem maior compreensão dos fatores que influenciam o desempenho dos alunos nas áreas e anos avaliados. Em 2013, cerca de 7,6 milhões de estudantes do ensino fundamental e médio de todas as unidades da federação fizeram as provas do Saeb.

O Saeb é composto por três avaliações externas em larga escala aplicadas pelo Inep: a Avaliação Nacional da Educação Básica (Aneb), a Avaliação Nacional do Rendimento Escolar (Anresc, mais conhecida como Prova Brasil) e a Avaliação Nacional de Alfabetização (ANA). A Aneb e a Anresc ocorrem a cada dois anos, quando são aplicadas provas de Língua Portuguesa e Matemática, além de questionários socioeconômicos aos alunos participantes e à comunidade escolar. Já a ANA é anual.

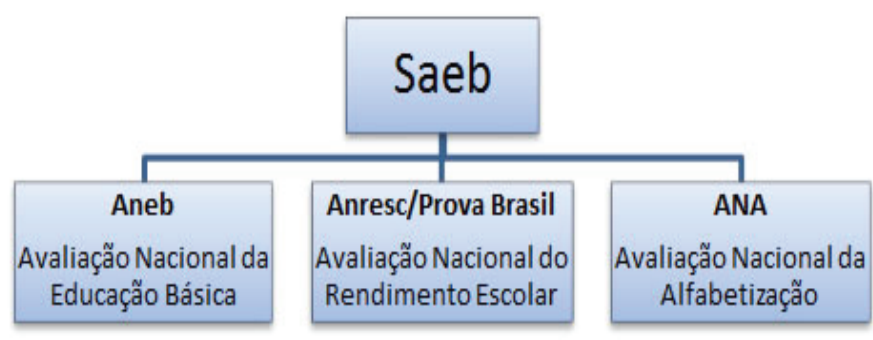


A Avaliação Nacional da Educação Básica (Aneb) abrange, de maneira amostral, alunos das redes públicas e privadas do País, em áreas urbanas e rurais, matriculados na $4^{\mathrm{a}}$ série $/ 5^{\circ}$ ano e $8^{\mathrm{a}}$ série $/ 9^{\circ}$ ano do ensino fundamental e no $3^{\circ}$ ano do ensino médio, tendo como principal objetivo avaliar a qualidade, a equidade e a eficiência da educação brasileira. Apresenta os resultados do País como um todo, das regiões geográficas e das unidades da federação. Com provas de leitura e matemática, foi realizada em 2013 por 246 mil estudantes do quinto e do nono anos (quarta e oitava séries) do ensino fundamental regular e do terceiro ano do ensino médio das redes pública e particular.

A Prova Brasil, composta por exames de leitura e matemática, é uma avaliação censitária que envolve os alunos da $4^{\mathrm{a}}$ série $/ 5^{\circ}$ ano e $8^{a}$ série $/ 9^{\circ}$ ano do ensino fundamental das escolas públicas das redes municipais, estaduais e federal, com o objetivo de avaliar a qualidade do ensino ministrado nas escolas públicas. Em 2013. a Prova Brasil foi aplicada a aproximadamente 4,7 milhões de estudantes. Participaram escolas com pelo menos 20 estudantes matriculados em turmas do quinto e do nono anos (quarta e oitava séries) do ensino fundamental regular de escolas públicas das zonas urbana e rural. Os resultados da Prova Brasil ampliam a gama de informações que subsidiam a adoção de medidas que superem as deficiências detectadas em cada escola avaliada.

\section{A Avaliação Nacional de Avaliação (ANA)} é uma avaliação censitária direcionada para unidades escolares e estudantes matriculados no $3^{\circ}$ ano do ensino fundamental das escolas públicas, fase final do Ciclo de Alfabetização, e insere-se no contexto de atenção voltada à alfabetização prevista no Pacto Nacional pela Alfabetização na Idade Certa (PNAIC). Tem como objetivo principal avaliar os níveis de alfabetização e letramento em Língua Portuguesa, alfabetização matemática e condições de oferta do Ciclo de Alfabetização das redes públicas. Foi aplicada pela primeira vez em 2013, onde foram avaliados cerca de 2,6 milhões de estudantes do terceiro ano do ensino fundamental de escolas públicas das zonas urbana e rural organizadas no regime de nove anos. $O$ exame foi aplicado em todas as turmas regulares e em uma amostra de turmas multisseriadas.

Esta avaliação produzirá indicadores que contribuam para o processo de alfabetização nas escolas públicas brasileiras. Trata-se de uma avaliação para além da aplicação do teste de desempenho ao estudante, uma vez que propõe, também, uma análise das condições de escolaridade que esse estudante teve, ou não, para desenvolver esses saberes. 


\section{EXAME NACIONAL PARA CERTIFICAÇÃO DE COMPETÊNCIAS DE JOVENS E ADULTOS (ENCCEJA)}

O Encceja constitui-se em um exame para aferição de competências, habilidades e saberes adquiridos no processo escolar ou extraescolar de jovens e adultos que não tiveram acesso aos estudos ou não puderam continuá-los na idade própria, sendo aplicado a brasileiros residentes no Brasil e no exterior. A participação neste exame é voluntária e gratuita. No Brasil e no exterior, o Encceja pode ser realizado para pleitear certificação no nível de conclusão do ensino fundamental para quem tem no mínimo quinze anos completos na data de realização das provas. No exterior, além da certificação no nível de conclusão do ensino fundamental, os interessados no exame podem pleitear a certificação no nível de conclusão do ensino médio, desde que tenham no mínimo dezoito anos completos na data de realização das provas.

\section{EXAME NACIONAL DO ENSINO MÉDIO (ENEM)}

O Enem tem como objetivo avaliar o desempenho do estudante ao final da educação básica, buscando contribuir para a melhoria da qualidade deste nível de ensino. É constituído por provas objetivas e de redação, contemplando quatro áreas do conhecimento: Matemática e suas tecnologias; Ciências da Natureza; Ciências Humanas; Linguagens e Códigos. As informações obtidas a partir dos resultados do Enem são utilizadas principalmente para estabelecer critérios de acesso do participante a programas governamentais, a exemplo do Programa Universidade para Todos (ProUni), do Fundo de Financiamento Estudantil (Fies) e do Ciência sem Fronteiras.

Em outubro de 2013, as provas do Enem foram realizadas em 1.661 municípios de todo o País. Cerca de 5,04 milhões de estudantes realizaram a prova, um aumento de 20\% em relação aos 4,17 milhões de participantes em 2012. Destes, 784.830 participantes indicaram na inscrição ao Enem que fariam as provas para obter 0 certificado de conclusão do ensino médio, e 60.320 atingiram os requisitos mínimos. O Enem também é aplicado para adultos submetidos a penas privativas de liberdade e adolescentes sob medidas socioeducativas.

Com a reformulação do Enem em 2009 e de sua utilização como forma de seleção unificada nos processos seletivos das universidades públicas federais, há indicações de que o exame tem possibilitado mais intensamente a democratização das oportunidades de acesso às vagas federais de ensino superior, a mobilidade acadêmica e a implementação de um processo isonômico de avaliação do desempenho dos estudantes em todo o território nacional.

\section{ÍNDICE DE DESENVOLVIMENTO DA EDUCAÇÃO}

Criado em 2007, o Índice de Desenvolvimento da Educação Básica (Ideb) é um indicador que combina os dados de fluxo escolar, especificamente as taxas de 
aprovação - obtidas a partir do Censo da Educação Básica - com os dados de desempenho escolar, fornecidos pela Prova Brasil e pelo Saeb. É calculado para cada uma das etapas de ensino e recebe valores de 0 a 10.

A série histórica de resultados do Ideb se inicia em 2005, quando foram estabelecidas metas bienais de qualidade a serem atingidas não apenas pelo País, mas também por escolas, municípios e unidades da federação. A lógica é a de que cada instância evolua de forma a contribuir, em conjunto, para que o Brasil atinja o patamar educacional da média dos países da Organização para a Cooperação e Desenvolvimento Econômico (OCDE). Em termos numéricos, isso significa progredir da média nacional 3,8, registrada em 2005 na primeira fase do ensino fundamental, para um Ideb igual a 6,0 em 2021, ano em que o Ideb do Brasil deve corresponder a um sistema educacional de qualidade comparável a dos países desenvolvidos.

Com o Ideb, ampliam-se as possibilidades de mobilização da sociedade em favor da educação, uma vez que o índice é comparável nacionalmente, calculado por rede de ensino e por escola, e expressa em valores os resultados mais importantes da educação: aprendizagem e fluxo.
Pelos dados do Ideb, é possível identificar quais são as redes de ensino municipais e as escolas que apresentam maiores fragilidades no desempenho escolar e que, por isso mesmo, necessitam de maior atenção, apoio financeiro e de gestão por parte do Governo Federal. O cálculo do Ideb é feito bianualmente. Desta forma, não existem valores para 2012 e o índice de 2013 tem publicação prevista para setembro de 2014.

Em 2011, o Brasil atingiu as metas estabelecidas para o período em todas as etapas do ensino básico - anos iniciais e anos finais do ensino fundamental e ensino médio. Nos anos iniciais (primeiro ao quinto), o Ideb nacional alcançou 5,0 em 2011. Ultrapassou não só a meta de 4,6, como também a proposta para 2013. que era de 4,9. Nessa etapa do ensino, a oferta é prioritariamente das redes municipais, que concentram 11,13 milhões de matrículas, quase $80 \%$ do total. Nos anos finais (sexto ao nono) do ensino fundamental, em 2011 o Ideb nacional atingiu 4,1 e ultrapassou a meta proposta de 3,9. Considerada tão somente a rede pública, o índice nacional chegou a 3,9 e também superou a meta de 3,7 prevista para essa esfera. Em relação ao ensino médio, incluídos ensino público e particular, os resultados foram igualados, em 2011, à meta nacional prevista de 3,7. 
IDEB- RESULTADOS E METAS|

\begin{tabular}{|l|r|r|r|r|r|r|}
\hline \multirow{2}{*}{ Etapas da Educação Básica } & \multicolumn{2}{|c|}{2007} & \multicolumn{2}{|c|}{2009} & \multicolumn{2}{c|}{2011} \\
\cline { 2 - 7 } & Meta & Realizado & Meta & Realizado & Meta & Realizado \\
\hline Anos Iniciais do Ensino Fundamental & 3,9 & 4,2 & 4,2 & 4,6 & 4,6 & 5,0 \\
\hline Anos Finais do Ensino Fundamental & 3,5 & 3,8 & 3,7 & 4,0 & 3,9 & 4,1 \\
\hline Ensino Médio & 3,4 & 3,5 & 3,5 & 3,5 & 3,7 & 3,7 \\
\hline
\end{tabular}

Fonte: Inep/MEC 22/01/2014

\section{CENSO DA EDUCAÇÃO SUPERIOR}

Este Censo, realizado anualmente pelo Inep, tem como objetivo oferecer à comunidade acadêmica e à sociedade em geral informações detalhadas sobre a situação e as grandes tendências do setor. A coleta de dados sobre este nível de ensino conta com a participação de todas as instituições de educação superior do País, por meio da utilização de um sistema on-line, em que são apuradas informações sobre as instituições de ensino superior, seus cursos de graduação presencial ou a distância, cursos sequenciais, vagas oferecidas, inscrições, matrículas, ingressantes e concluintes, além de informações sobre docentes nas diferentes formas de organização acadêmica e categoria administrativa. O Censo da Educação Superior coleta, ainda, dados financeiros e de infraestrutura, compreendendo bibliotecas, laboratórios, instalações, equipamentos e outros recursos institucionais, a fim de oferecer informações detalhadas sobre a situação atual e as grandes tendências desse nível de ensino no País.

Os dados são coletados a partir do preenchimento dos questionários, por parte das Instituições de Ensino Superior (IES) e por importação de dados do Sistema e-MEC. Durante o período de preenchimento do questionário, os pesquisadores institucionais (PIs) podem fazer, a qualquer momento, alterações ou inclusões necessárias nos dados das respectivas instituições. Após esse período, o Inep verifica a consistência dos dados coletados. O sistema do Censo é então reaberto para conferência e validação dos dados pelas IES. Passado esse período de validação ou correção das informações prestadas pelas IES, o Inep realiza rotinas de análise na base de dados do Censo para conferir as informações. Após essa fase de conferência, em colaboração com os pesquisadores institucionais, o Censo é finalizado. Os dados são divulgados e a Sinopse Estatística é publicada. Depois disso não pode mais haver alteração nas informações, pois passam a ser estatísticas oficiais.

Este Censo proporciona anualmente diagnósticos para subsidiar a formulação de políticas para a educação superior, além de propiciar o acompanhamento, a avaliação e o fomento do sistema deste nível de ensino. 


\section{AVALIAÇÃO DA EDUCAÇÃO SUPERIOR - INSTITUIÇÕES E CURSOS}

De acordo com o artigo 206, inciso VII da Constituição Federal de 1988, o ensino será ministrado tendo por base, entre outros, o princípio da garantia de padrão de qualidade. Ainda com relação a tal matéria, em seu artigo 209, esse instrumento legal admite a livre oferta de ensino pela iniciativa privada, desde que atendidas as condições de cumprimento das normas gerais da educação nacional, a autorização e avaliação de qualidade pelo poder público, disposição esta corroborada pelas Diretrizes e Bases da Educação Nacional (LDB) $)^{3}$.

Nesse contexto, o MEC atua na fiscalização e manutenção do padrão de qualidade da oferta do ensino superior pelo Sistema Federal de Ensino, nos termos do Decreto ${ }^{\circ}$ 5.773/2006, que estrutura a ação do poder público no que concerne ao funcionamento da educação superior em torno de um tripé de funções: regulação, avaliação e supervisão, estabelecendo mecanismos processuais de conexão necessária entre elas, de modo que os indicadores de qualidade insuficiente dos processos de avaliação geram consequências diretas em termos de regulação - impedindo a aber- tura de novas unidades ou cursos - e de supervisão, dando origem à aplicação de penalidades e, no limite, ao fechamento de instituições e cursos.

No que diz respeito à avaliação, a qualidade das Instituições de Ensino Superior (IES), bem como de seus cursos, é aferida pelo Sistema Nacional de Avaliação da Educação Superior (Sinaes), que tem por objetivo assegurar o processo nacional de avaliação, com vistas, entre outras finalidades, à melhoria da qualidade da educação superior.

O Sinaes opera por meio de processos avaliativos que atuam em três dimensões complementares e que dialogam entre si: institucional, de cursos e do desempenho dos estudantes. Por sua vez, tais processos compreendem: i) a avaliação interna e externa das IES; ii) a avaliação dos cursos de graduação; e iii) a avaliação do desempenho acadêmico dos estudantes de cursos de graduação.

A avaliação institucional divide-se em duas modalidades: autoavaliação - coordenada pela Comissão Própria de Avaliação (CPA) de cada instituição e orientada pelas diretrizes e pelo roteiro da autoavaliação institucional da Comissão Na- 
cional de Avaliação da Educação Superior (CONAES) -, e avaliação externa, realizada por comissões designadas pelo Inep. Os instrumentos de avaliação externa operam com dez dimensões: i) Missão e PDI; ii) Política para o ensino, a pesquisa, a pós-graduação e a extensão, iii) Responsabilidade social da IES; iv) Comunicação com a sociedade, v) As políticas de pessoal, as carreiras do corpo docente e técnico-administrativo; vi) Organização de gestão da IES; vii) Infraestrutura física; viii) Planejamento de avaliação; ix) Políticas de atendimento aos estudantes; $x$ ) Sustentabilidade financeira. Os resultados variam de 1 a 5, sendo considerado satisfatório o desempenho maior ou igual a três.

Cabe ressaltar que a operacionalização dos procedimentos de avaliação é de responsabilidade do Inep, ao qual cabe decidir sobre o agendamento de avaliações de cursos, levando-se em conta as necessidades e a conveniência de tal avaliação. Os processos avaliativos são coordenados e supervisionados pela CONAES.

O Sinaes opera com diversos indicadores referentes aos cursos e às IES, e para esse intento possui uma série de instrumentos complementares, com destaque para o e-MEC, sistema eletrônico de fluxo de trabalho e gerenciamento de informações relativas aos processos de regulação, avaliação e supervisão da educação superior no sistema federal de educação, e o Cadastro e-MEC de Instituições e Cursos Superiores que consolida disposições sobre indicadores de qualidade, banco de avaliadores
(Basis), o Exame Nacional de Desempenho de Estudantes (Enade) e outras disposições.

Em relação aos cursos, os indicadores informados são a nota do curso no Enade, o Conceito Preliminar de Curso (CPC) e o Conceito de Curso (CC). O CPC é um indicador composto a partir dos resultados do Enade e por fatores que consideram a titulação dos professores, o percentual de docentes que cumprem regime parcial ou integral (não horistas), recursos didático-pedagógicos, infraestrutura e instalações físicas. O conceito, que vai de 1 a 5, é um indicador da qualidade dos cursos de graduação no País, sendo o conceito maior ou igual a três considerado satisfatório.Já o CC é um indicador composto a partir da avaliação in loco das condições de oferta do curso, realizada por comissões de especialistas especialmente designadas pelo Inep, cujos instrumentos contemplam três dimensões relacionadas aos cursos: i) organização didático-pedagógica, ii) corpo docente e iii) instalações físicas. Os resultados variam de 1 a 5, sendo considerado satisfatório o desempenho maior ou igual a três.

O Enade tem como objetivo avaliar o conhecimento dos alunos em relação ao conteúdo previsto nas diretrizes curriculares do respectivo curso de graduação, suas habilidades e competências. Participam do exame os alunos ingressantes e concluintes dos cursos avaliados. Os resultados do Enade são considerados na composição de índices de qualidade rela- 
tivos aos cursos e às instituições (como o (PC e o IGC).Tais resultados são classificados de 1 a 5, sendo o desempenho igual ou maior que três considerado satisfatório. O exame é obrigatório para os alunos selecionados e condição indispensável para a emissão do histórico escolar.

Quanto às instituições de ensino superior, os indicadores informados são o Índice Geral de Cursos da instituição (IGC) e o Conceito Institucional (CI). O IGC é um indicador que sintetiza a qualidade de todos os cursos de graduação e pós-graduação stricto sensu (mestrado e doutorado) de cada universidade, centro universitário ou faculdade do País. No que se refere à graduação, é utilizado o CPC dos cursos; e no que se refere à pós-graduação, é utilizada a Nota Capes, que expressa os resultados da Avaliação dos Programas de Pós-graduação, realizada pela Coordenação de Aperfeiçoamento de Pessoal de Nível Superior (Capes). Os resultados variam de 1 a 5, sendo o desempenho maior ou igual a três considerado satisfatório. Já o Cl é o conceito resultante da avaliação in loco das condições de oferta dos cursos pela IES, realizada a cada ciclo avaliativo.

Cabe destacar que todos os indicadores aferidos pelo Sinaes são renovados periodicamente. Os conceitos do Enade e do CPC de cada curso são calculados a cada três anos e o IGC é atualizado anualmente, a partir do CPC dos cursos avaliados. Também os conceitos de avaliação são periódicos, sendo atualizados sempre que a IES protocola pedidos de renovação dos atos autorizativos, submetendo-se a procedimentos de verificação in loco. As informações obtidas com as avaliações são utilizadas: pelas IES para orientação da sua eficácia institucional e efetividade acadêmica e social; pelos órgãos governamentais para orientar políticas públicas; e pelos estudantes, pais de alunos, instituições acadêmicas e público em geral, para orientar suas decisões quanto à realidade dos cursos e das instituições.

Os resultados das avaliações possibilitam traçar um panorama da qualidade dos cursos e instituições de educação superior no País. Além disso, os resultados advindos da avaliação subsidia tanto o processo de regulamentação e supervisão da educação superior, exercido pelo MEC, como garante transparência dos dados sobre a qualidade da educação superior a toda sociedade. Dessa forma, a avaliação tornou-se um pilar fundamental da regulação e da supervisão do sistema federal de educação superior, compondo um marco regulatório coerente que dota o poder público de maior capacidade de indução à qualidade.

\section{PROGRAMA INTERNACIONAL DE AVALIAÇÃO DE ESTUDANTES (PISA)}

O Pisa, desenvolvido e coordenado internacionalmente pela Organização para Cooperação e Desenvolvimento Econômico 
(OCDE), tem como objetivo avaliar se os estudantes, aos 15 anos de idade, adquiriram conhecimentos e habilidades essenciais para uma participação plena em sociedades modernas. O Inep atua como coordenador desta avaliação no Brasil, que ocorre a cada três anos e abrange três áreas de conhecimento - Leitura, Matemática e Ciências. Em 2012, a avaliação foi aplicada a quase 20 mil estudantes de 767 escolas brasileiras, tendo ênfase em Matemática. Os resultados do Pisa 2012, divulgados em 2013, demonstram que o Brasil é o país que mais avançou no resultado de Matemática entre todos os avaliados, passando de 356 para 391 pontos no período entre 2003 e 2012. O Brasil também teve destacado crescimento nas outras áreas avaliadas, como Ciências e Leitura. Além disso, a melhora no desempenho foi acompanhada da inclusão de mais de 420 mil estudantes com 15 anos. O número de matrículas de alunos na educação básica nessa faixa etária saltou de 65\% da edição de 2003 para 78\% em 2012 , sendo esta a segunda maior taxa de inclusão, atrás apenas da Indonésia.

\section{SISTEMA INTEGRADO DE}

\section{MONITORAMENTO, EXECUÇÃO E CONTROLE DO MINISTÉRIO DA EDUCAÇÃO (SIMEC)}

O MEC tem uma matriz de relacionamento muito complexa: são 27 Secretarias Es- taduais de Educação, 5.569 Secretarias Municipais de Educação e aproximadamente 155 mil escolas públicas. Para este atendimento, conta com uma estrutura organizacional que compreende 145 unidades orçamentárias, com destaque para as seis secretarias da administração direta ${ }^{4}$, duas subsecretarias ${ }^{5}$ e oito entidades vinculadas, destacando-se a Coordenação de Aperfeiçoamento de Pessoal de Nível Superior (Capes), o Fundo Nacional de Desenvolvimento da Educação (FNDE) e o Instituto Nacional de Estudos e Pesquisas Educacionais Anísio Teixeira (Inep). Conta ainda com 38 Institutos Federais de Educação, Ciência e Tecnologia (440 campi em funcionamento), dois Centros Federais de Educação Tecnológica, 59 Universidades Federais (287 campi em funcionamento) e 46 Hospitais Universitários.

Soma-se a este contexto o cenário de dinamismo e aporte de recursos na área educacional ocorrido nos últimos anos, principalmente a partir da criação do Plano de Desenvolvimento da Educação (PDE) em 2007. A ampliação de recursos para a educação passou de $4,7 \%$ do PIB em 2000 para 6,1 \% do PIB em 2011, e o orçamento do MEC apresentou um aumento de $82 \%$ no período de vigência do PPA 2008-2011.

Essa realidade tem demandado do Ministério buscar constantemente o aprimo- 
ramento do seu planejamento e práticas mais flexíveis de gestão. Portanto, em 2005, a Subsecretaria de Planejamento e Orçamento (SPO), órgão subordinado diretamente à Secretaria Executiva do MEC, desenvolveu e implantou um sistema próprio, com uma solução tecnológica para acompanhar a execução das ações governamentais desde a sua concepção até a efetiva realização física e financeira, além de outras propriedades e atribuições. Trata-se do Sistema Integrado de Monitoramento, Execução e Controle do Ministério da Educação (SIMEC) com função InfraSIG, ou seja, opera como alimentador de outros sistemas do Governo Federal, que foi elaborado para ser uma ferramenta de organização e integração do gerenciamento dos programas governamentais no processo de monitoramento e avaliação do PPA, mediante a sistematização informacional da execução física dos programas e das ações governamentais.

O SIMEC pode ser concebido como um modelo de governança do setor público, a partir da redefinição dos processos de planejamento e gestão institucionais do MEC que possibilita:
- A integração entre as ferramentas de planejamento e gestão orçamentária, e estas a instrumentos de monitoramento de atividades estratégicas do Ministério, mediante desenvolvimento e implantação de nova metodologia de integração plano-orçamento;

- O fortalecimento da atividade de planejamento e gestão no âmbito do MEC, por ser uma ferramenta permanente, suprimindo iniciativas pontuais e esparsas, além de facilitar a tomada de decisão;

- A redefinição do padrão de relacionamento e apoio às esferas estaduais e municipais, contribuindo para o fim da política de "balcão", uma vez que o processo de apresentação de propostas por esses entes a partir da implantação dos módulos PAR, Plano de Metas e Brasil Profissionalizado ganhou maior transparência e racionalidade;

- O apoio a atividades de supervisão de obras que recebem recursos do MEC, contribuindo para uma gestão mais eficiente dos recursos públicos; e

4 São elas: Secretaria de Educação Superior (SESU); Secretaria de Educação Profissional e Tecnológica (SETEC); Secretaria de Educação Básica (SEB); Secretaria de Educação Continuada, Alfabetização, Diversidade e Inclusão (SECADI); Secretaria de Articulação com os Sistemas de Ensino (SASE); Secretaria de Regulação e Supervisão da Educação Superior (SERES).

5 Subsecretaria de Planejamento e Orçamento (SPO) e Subsecretaria de Assuntos Administrativos (SAA).

Revista Brasileira de Monitoramento e Avaliação | Número 5 | Janeiro-Junho de 2013 
- A adoção de solução tecnológica que possibilita a criação e a substituição de módulos conforme a necessidade dos gestores, conferindo-lhe flexibilidade e caráter evolutivo, bem como a replicação da metodologia e da plataforma a outros órgãos e esferas de governo ${ }^{6}$.

O SIMEC é composto por módulos com características, funções, públicos-alvo e ferramentas específicas que compreendem diferentes áreas do Ministério: administrativa, ciclo de planejamento, orçamento e finanças, gestão de políticas públicas, acompanhamento de obras e painéis estratégicos de monitoramento e controle. As informações do SIMEC atendem a alta gestão, assim como às diretorias e áreas técnicas. Ao longo dos anos foram criados novos módulos com funções correlacionadas tanto ao monitoramento e avaliação, quanto à execução orçamentária e financeira das ações dooMEC, resultando emnuma robusta plataforma com um quantitativo superior a 50 módulos.

A figura abaixo representa a Tela inicial do SIMEC, com informações sobre os seus módulos, informes, além de um campo que permite que o usuário solicite seu cadastro ou peça recuperação de senha e, obviamente, entre no sistema propriamente dito (login). O sistema SIMEC somente é acessado por usuários previamente cadastrados. O acesso é realizado mediante senha pessoal que habilitá o usuário aos módulos para os quais tenha sido previamente autorizado. 
- FIGURA 1: TELA INICIAL DO SIMEC, DISPONÍVEL EM hTTP://SIMEC. MEC.GOV.BR

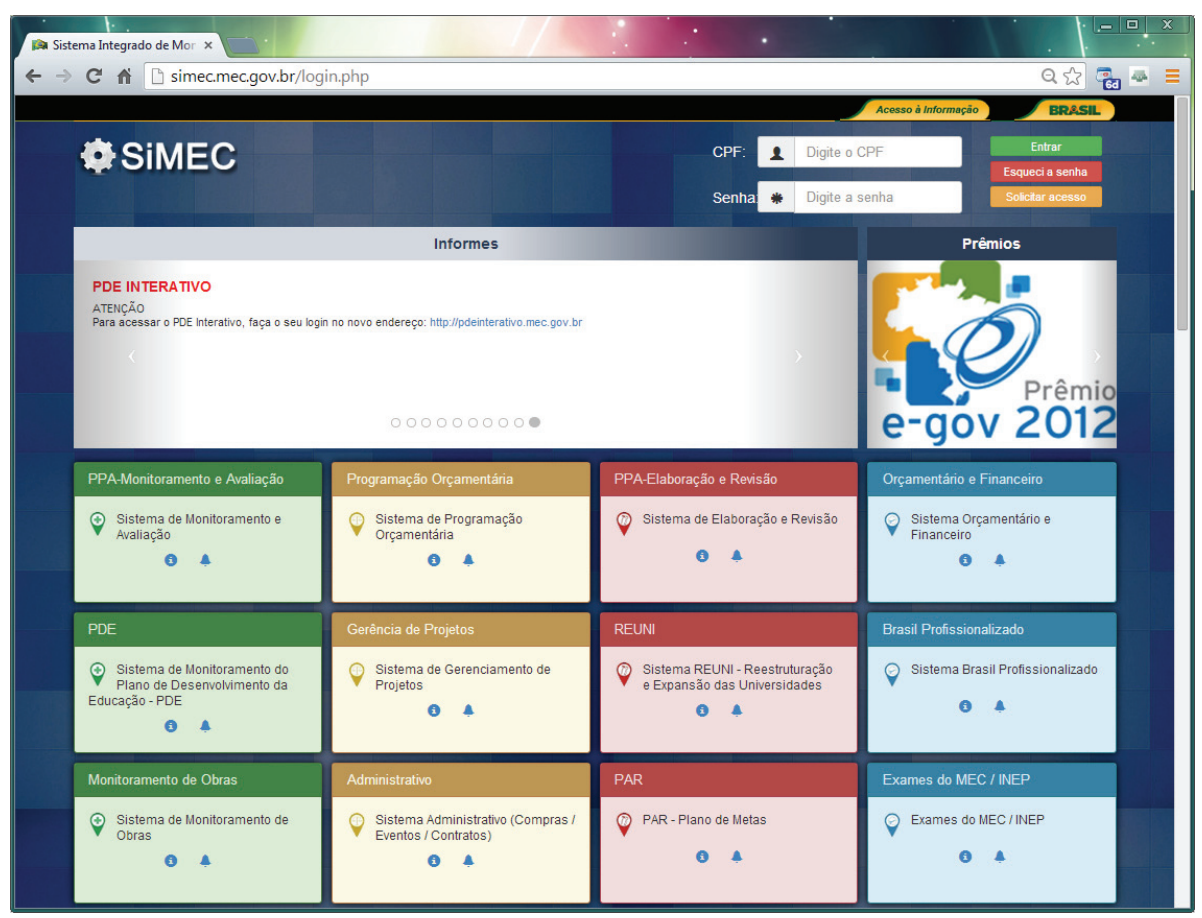

6 PONTES E NÉHME, 2009, p.176-177.

Revista Brasileira de Monitoramento e Avaliação | Número 5 | Janeiro-Junho de 2013 
Alguns dos Módulos do SIMEC são utilizados por parceiros como universidades, estados e municípios. O sistema possui mais de 270 mil usuários cadastrados, dos quais mais de 220 mil são ativos, incluindo todos os governos de estados e municípios brasileiros, além das unidades orçamentárias do MEC. Com relação ao acesso, são computados 6.325 usuários distintos por dia e 90.766 usuários distintos por mês. Portanto, o SIMEC é um canal direto, rápido e efetivo entre o ministério e todas as demais esferas e instituições envolvidas com a oferta de educação no Brasil.

Decorridos mais de oito anos de sua implantação, a criação do SIMEC tem contribuído para o MEC, gradativamente, re- tomar o seu planejamento e modernizar a sua gestão, ao conferir mais agilidade, racionalidade e credibilidade ao processo gerencial, como também padronizar as atividades inerentes ao fluxo de informações físicas e financeiras, repercutindo na elevação do nível de satisfação dos seus usuários internos e externos e na ampliação de sua capacidade de análise sobre a situação real da educação no país. Além disso, a criação de seus diversos módulos tem possibilitado a superação de alguns gargalos da rotina de trabalho do MEC, aumentando o nível de interoperabilidade entre as suas diversas áreas, fato este que tem justificado a construção de novos módulos e o aperfeiçoamento dos já existentes. 


\section{Considerações finais}

É incontestável que os resultados das avaliações assumem importante papel não apenas para o planejamento educacional, mas também por sua contribuição para a concretização de um modelo de accountability que possa configurar-se em um sistema de responsabilização e controle social. Os sistemas de avaliação e informação educacional cumprem, ainda, um papel estratégico no desenho prospectivo de cenários, auxiliando enormemente a formulação de novas políticas e programas que possam responder às tendências de mudanças observadas. No que concerne à educação, pode-se afirmar que o Brasil conta atualmente com sistemas informacionais modernos, atualizados e confiáveis de coleta de dados educacionais, gerando indicadores que possibilitam monitorar, avaliar e gerenciar as políticas para a educação.

A institucionalização da prática de avaliação, bem como a ampla compreensão e apropriação de seus resultados, é elemento fundamental para alcançarmos os objetivos propostos pelas ações governamentais, além de contribuir para o aper- feiçoamento e legitimidade da ação do Estado. Observa-se, no caso específico das avaliações educacionais, que nos últimos anos os processos avaliativos de amplo espectro, relativos ao desempenho de alunos da educação básica (ensino fundamental e médio), da educação superio, e de instituições de ensino estão melhor qualificados. É inegável que o Brasil tem avançado no que diz respeito a essas avaliações.

Atualmente, um dos temas presentes entre as principais discussões do governo é a sustentabilidade da gestão pública e a importância de utilizá-la como critério para orientar as ações de governo. Neste contexto, os levantamentos periódicos e a produção de dados e informações estatístico-educacionais realizados pelo MEC, que retratam a realidade do setor educacional de forma ágil e fidedigna, têm propiciado mudanças que se refletem na nova agenda do debate educacional e constituem instrumentos básicos de avaliação, planejamento e auxílio ao processo decisório para o estabelecimento de políticas de melhoria da educação brasileira. 